\title{
Representaciones sobre lo indígena y su vínculo con tendencias culturales globalizadas ${ }^{*}$
}

\author{
Jean Paul Sarrazin ** \\ Recibido: 2015-02-27 -Enviado a pares: 2015-03-09 \\ Aprobado por pares: 2015-03-30 Aceptado: 2015-04-05
}

\begin{abstract}
Resumen
En este artículo se analizan representaciones sobre lo indígena manifiestas en un sector de la población no indígena de Colombia, donde el chamanismo es un tema recurrente y donde las culturas indígenas son representadas como poseedoras de una sabiduría espiritual, alternativa y benéfica para la sociedad occidental. El análisis de este tipo de ideas permite advertir similitudes con los discursos utilizados en diferentes latitudes para representar otras alteridades étnicas, lo cual no se debe a semejanzas objetivas entre los grupos étnicos, sino a similitudes socioculturales existentes entre las personas que se representan así lo étnico. Los resultados llevan a concluir que este indigenismo es la manifestación local de una ideología globalizada, centrada en los ideales y necesidades del yo moderno.
\end{abstract}

Palabras clave: indigenismo, globalización, representaciones sociales, modernidad, alteridad.

* Este artículo surge en parte de la investigación que realizó el autor en el marco de su Doctorado en Sociología de la Université de Poitiers, Francia, y gracias al apoyo de una beca del Institut de Recherche pour le Développement, París. (ESPAÑA)

** Antropólogo, magíster en Migraciones y Relaciones Interétnicas y Doctor en Sociología. Docenteinvestigador vinculado al Departamento de Sociología de la Universidad de Antioquia.E-mail: jpsarra@ yahoo.com 


\title{
Representations about the indigenous and their link with globalized cultural trends
}

\begin{abstract}
This article describes a set of representations about native cultures manifested in a sector of the non-indigenous population of Colombia, where shamanism is increasingly mentioned, and where natives are imagined as having a spiritual and alternative wisdom beneficial to western societies. The analysis of these and other ideas reveals similarities with the narratives used to represent other indigenous or ethnic cultures in different latitudes. Those similarities, it is argued, do not come from objective cultural resemblances between ethnic groups; they come from common sociocultural characteristics of the people who construct those representations of the ethnic. These findings support the conclusion that this kind of indigenism is the local manifestation of a globalized ideology centered on the ideals and needs of the modern self.
\end{abstract}

Key words: indigenism, globalization, social representations, modernity, otherness.

\section{Representações do indígena e sua ligação com tendências culturais globalizadas}

\section{Resumo:}

Neste artigo são analisadas as representações do indígena reveladas num setor da população não-indígena da Colômbia, onde o xamanismo é um tema recorrente e onde as culturas indígenas são representadas como possuidoras de uma sabedoria espiritual, alternativa e benéfica para sociedade ocidental. A análise dessas ideias permite perceber semelhanças com os discursos usados em diferentes latitudes para representar outras alteridades étnicas, o que não se deve a semelhanças objetivas entre grupos étnicos, mas a semelhanças socioculturais existentes entre as pessoas que representam desta forma o étnico. Os resultados levam à conclusão que este indigenismo é a revelação local de uma ideologia global, focada nos ideais e necessidades do alter ego moderno.

Palavras-chave: indigenismo, globalização, representações sociais, modernidade, alteridade. 


\section{Introducción}

En este artículo se analiza - desde una perspectiva sociológica- un conjunto de discursos e imágenes que se reproducen acerca de lo indígena en un sector de la población colombiana no indígena, constituyendo así lo que llamaremos una forma contemporánea de indigenismo. Cabe aclarar desde ya que el término "indigenismo" es polisémico y es utilizado en diferentes contextos sociales de maneras variadas, denotando proyectos políticos y luchas de pueblos marginalizados cuyos modos de vida, pensamiento e integridad física han sido atacados'. Aunque acá no nos referiremos a esas realidades indígenas, ello no significa que se consideren sin importancia. Coincidimos con Alcida Ramos (1998), para quien el término "indigenismo" no necesariamente tiene que limitarse al activismo indígena o a las políticas oficiales dirigidas a comunidades indígenas. El uso que queremos darle al término "indigenismo" lo sostendremos en un sentido similar al de la palabra "orientalismo", tal como lo hace Ramos (2012). En estas construcciones sobre la alteridad juegan un papel diferentes tipos de actores, entre los cuales se pueden contar: "los medios de comunicación, la literatura de ficción, las actuaciones de la Iglesia y de activistas de los derechos humanos, los análisis antropológicos y las posiciones de los propios indios que pueden negar o corroborar ese conjunto de imágenes sobre el indio" (Ramos 2012, p. 165). Por demás, añade la autora (p. 166), existen "tantos 'indios' cuantos sean los agentes interesados en construir ese edificio fascinante, multifacético y, a veces, tan imposible de descifrar como una obra de Escher. Ese es el indigenismo que llegó al siglo XXI".

Evidentemente, no todos los tipos de representaciones sobre lo indígena pueden ser tenidos en cuenta en un artículo, como tampoco podemos analizar en este espacio limitado a todos los actores que intervienen en dichos procesos. El presente estudio se focaliza en los discursos, valoraciones positivas y actitudes que se observan a propósito de lo indígena entre urbanitas que -sin pretender generalizar- pertenecen a clases medias y altas en Colombia. Para precisar aún más, el análisis gira alrededor de una idea recurrente y central en los discursos observados: las culturas indígenas poseerían una forma de sabiduría benéfica y enriquecedora para la sociedad "occidental"2. Se trata acá de aportar a la comprensión del proceso que llevó a que se difundiera este tipo de ideas e imágenes positivas sobre lo indígena, considerando particularmente el papel que juegan los distintos medios de comunicación consumidos por la población de estudio, es decir, un cierto tipo de indigenistas -que llamaremos así aunque ellos no necesariamente se identifiquen con ese apelativo-.

Como se explicará, este tipo de valoraciones evocadas por una población local no surgen de manera aislada. Al contrario, esta es la manifestación local de un fenómeno relativamente reciente en la historia moderna que se ha difundido a escala global. En efecto, la Modernidad tardía permite la difusión globalizada -mas no de manera uniforme ni entre

1 Agradecemos a los evaluadores por señalar la importancia de insistir en esta necesaria aclaración. Sobre los movimientos sociales e indígenas de décadas pasadas, ver por ejemplo Escobar 1992; Gros 2000; Findji 1992.

2 Las comillas, en casos como este, se usan para citar expresiones extraídas de los discursos analizados. 
todas las personas del planeta- de elementos simbólicos que constituyen parcialmente las concepciones locales de la identidad y de la alteridad, de lo que es "Occidente" o de lo que son "las culturas indígenas". Observamos también en nuestros días la difusión a escala global de ciertos valores, es decir, creencias sobre lo que es deseable, lo importante, lo bueno... o sus contrarios. Así, un citadino intelectual de clase media-alta puede no compartir mucho con el obrero que ve todos los días al salir de su casa, pero sus gustos e ideales de vida pueden ser muy similares a las de otro citadino intelectual de clase media-alta viviendo al otro lado del océano. Concomitantemente, existen imaginarios sobre lo étnico muy similares en distintas latitudes del globo, y diferentes formas culturales etiquetadas como "étnicas" son representadas como fuentes de sabiduría y bienestar para el individuo occidental. Todo ello, argumentaremos, implica un proceso de traducción y reinterpretación que se inscribe en tendencias culturales muy modernas.

Contrariamente a lo que se suele pensar, las similitudes en los discursos sobre lo étnico que se observan en países como Colombia, Chile, Francia, Islandia, Holanda o Estados Unidos, no se deben a supuestas similitudes culturales entre los grupos étnicos representados (sean de Suramérica, Norteamérica o la India), sino a algunas características socioculturales comunes a los sujetos que -aunque no se conozcan y vivan a miles de kilómetros de distancia- comparten cierto tipo de imaginarios positivos sobre lo étnico.

Estos sectores de la población, como veremos, pueden ser considerados como occidentales u occidentalizados, gozan de una condición económica favorable, poseen un capital cultural relativamente elevado (de Educación Superior), y tienen acceso al mismo tipo de discursos e imágenes a través de los medios de comunicación globalizados. Dicho de otro modo, estos individuos están conectados a una red globalizada de significantes con los cuales se construyen en parte sus representaciones de la alteridad. Estamos de acuerdo con Hall (1991), para quien las nuevas formas de globalización tienen mucho que ver con la nueva cultura de los "mass-media", una cultura cuyo centro - precisa el autor- es Occidente, donde el inglés es la principal lengua, donde se valora el consumo de diferentes formas culturales (como religiones o espiritualidades), y donde estar a la vanguardia intelectual es admirar el pluralismo.

En la misma línea, Amselle (2005) plantea que la construcción de las identidades culturales está fuertemente influenciada por el consumo local de productos y de información "importados" (p. 23). Así, por ejemplo, a través del cine o el Internet, los individuos pueden alimentar sus imaginarios sobre la identidad y la alteridad. A propósito de casos que también se han observado en otras regiones del planeta, Comaroff y Comaroff (2009) señalan que las dinámicas neoliberales del mercado han llevado a la profusión de elementos culturales que circulan en tanto que mercancías. No es solo que la cultura se mercantilice, sino que estamos ante la multiplicación globalizada de mercancías culturales: discursos, imágenes, rituales, experiencias... En ese proceso, las marcas de alteridad pasaron de ser algo despreciado, a ser "mercancías inmateriales" (ibíd.) deseadas, buscadas, valoradas desde distintos sectores de las sociedades del mundo. 
Muchas de las representaciones sobre lo indígena o lo étnico se construyen a través del flujo y apropiación de elementos que el mercado pone a circular, y se expresan mediante lenguajes translocales (no étnicos). Aunque muchos actores lo nieguen rotundamente, la valoración de las culturas indígenas -por más "tradicionales", "milenarias" o "ancestrales" que se consideren- se fundamenta sobre imaginarios de lo étnico de facción reciente que circulan en un mercado globalizado (y neoliberal) de "mercancías inmateriales".

Al destacar la importancia de los medios de comunicación en este proceso, sin embargo, no pretendemos decir que estos han determinado de manera definitiva y mecánica las ideas de las poblaciones receptoras; es evidente que estas últimas juegan su papel creativo en la recepción, reinterpretación y uso de los símbolos. De otra parte, hablar de los flujos culturales y la reproducción de ciertas ideas entre ciertas poblaciones no equivale a anunciar la homogeneización cultural del mundo. Retomando a Sahlins (1997), los flujos globales se diversifican de acuerdo con los esquemas culturales particulares (p. 133) y, como señala Trouillot (2011, p. 60), en estos tiempos de globalización, la creciente desigualdad conlleva también grandes diferencias socioculturales.

\section{Metodología}

Las representaciones sobre lo indígena analizadas aquí provienen, por un lado, de distintas fuentes de información consumida entre 2004 y 2014 por residentes de Bogotá, lo cual incluye libros, prensa, televisión, Internet, conferencias o charlas informales relacionadas con el tema de lo indígena. Por otro lado, durante dicho período también se realizaron entrevistas no directivas con más de 40 urbanitas, quienes han manifestado verbalmente o a través de sus prácticas, una valoración de lo indígena ${ }^{3}$. Estas entrevistas fueron iniciadas por una pregunta abierta del tipo: "¿qué opinión tiene sobre las culturas indígenas?", a lo cual se sucedían otras preguntas que buscaban una conversación extendida donde el sujeto ampliara, ejemplificara o explicara con más detalle su pensamiento ${ }^{4}$.

Lo anterior fue complementado con observaciones etnográficas en los contextos sociales que frecuentan quienes producen y reproducen ${ }^{5}$ este tipo discursos. Las observaciones etnográficas permitieron, además, correlacionar las expresiones de los sujetos con ciertas características culturales y sociales (capital económico y capital cultural especialmente).

Siendo nuestro fin el de comprender cómo llegan los urbanitas a representarse lo indígena de manera positiva, es decir, cómo se constituye su ideología indigenista, hemos llevado a cabo un acercamiento de tipo fenomenológico (en el sentido en que lo plantean

3 Puesto que no se trata de una muestra suficientemente grande como para tener validez estadística, no pretendemos decir que la ideología acá descrita sea representativa de todo un sector de la población, ni de una clase social, ni que sea propia de un grupo etario en particular.

4 Esto corresponde con el concepto de "entrevista etnográfica" explicitado por Guber (2001, Capítulo 4).

5 El concepto de reproducción utilizado acá no debe confundirse con el de producción de copias idénticas. Al contrario, cuando se habla de reproducción, siempre se asume que hay modificaciones, tal como se ocurre en la naturaleza: los hijos nunca son copias idénticas de sus padres. 
Berger y Luckmann, 2003) que nos permita comprender las construcciones de la realidad y el sentido de las experiencias vividas subjetivamente por los individuos, en la medida en que aquellas contribuyen a estructurar y legitimar sus opiniones sobre lo indígena.

Luego de conocer las principales expresiones de este indigenismo y de comprender los conceptos clave en sus discursos, se presentan en este artículo las similitudes que existen entre el indigenismo local, y los discursos utilizados para representar otras culturas indígenas o étnicas en diferentes lugares del mundo, comparación que se logra a través de la revisión de una vasta literatura (de la cual se citan algunas de las referencias más significativas) proveniente de varios países. La constatación de esas similitudes permite plantear que el indigenismo al cual hacemos referencia es una manifestación local de ciertos discursos e imágenes que circulan a escala global, los cuales son readaptados a las realidades locales gracias a la "imaginación"6 de los sujetos.

\section{Contexto histórico e institucional}

El indigenismo contemporáneo llama particularmente la atención pues, hasta hace solo unas décadas, y como herencia del pensamiento colonial, los indígenas eran descritos como "salvajes" o una "raza inferior", seres que había que cristianizar, civilizar y educar (Pineda, 2002). Por lo que respecta a su religión, mientras que actualmente es el "chamanismo" uno de los temas que más contribuye a la construcción de una imagen positiva de lo indígena (razón por la cual lo analizaremos particularmente), ese mismo chamanismo en el pasado fue considerado como brujería diabólica (Uribe, 2002) o curandería propia de charlatanes (Reichel-Dolmatoff, 1993).

Hoy, un movimiento casi opuesto se ha desarrollado, pretendiendo compensar con términos positivos todo lo negativo que se dijo antes. Así, del "indio atrasado" pasamos al "indígena" cuya "cultura milenaria" es digna de respeto y cuya sabiduría es importante rescatar. Consecuentemente, ya nadie osa proponer-como sucedía hace unas décadasun programa educativo cuyo fin explícito sea la erradicación de sus tradiciones. Creyendo combatir la discriminación en contra de los indígenas, múltiples programas, acciones políticas y leyes multiculturalistas pretenden hoy promover su protección y respeto. Adicionalmente y contradiciendo viejos modelos de imposición de una cultura "blanca" u "occidental", desde los años 1980 se invoca cada vez con más fuerza el lema de la interculturalidad, la cual puede ser definida como "la apropiación selectiva de conceptos entre diferentes culturas para construir un diálogo pluralista entre iguales" (Rappaport, 2008, p 5). La diversidad multicultural se erige desde hace unas tres décadas como un valor primordial para el país, valor que de hecho es nombrado oficialmente como riqueza de la nación. Pero la principal manifestación oficial de esta nueva visión es la Constitución de 1991, la cual afirma desde sus primeras líneas que "el Estado reconoce y protege la diversidad étnica y cultural de la Nación" (artículo 7). Se trata, parafraseando las palabras del entonces Presidente de la República, de un reconocimiento oficial e institucional al

6 En el sentido de Appadurai (2001), como un proceso que se da en los flujos e intercambios de la modernidad globalizada, pero que involucra, por supuesto, la creatividad local. 
hecho de que las culturas indígenas deben ser respetadas, y sus saberes deben ser tenidos en cuenta (Gaviria, 1993).

Estos cambios en el país son la manifestación local de un fenómeno transnacional. El caso de Colombia se suma a una verdadera ola de transformaciones constitucionales a favor del multiculturalismo en varios países latinoamericanos como Nicaragua (1987), Brasil (1988), México (1992), Perú (1993), Bolivia (1994). Pero el fenómeno tiene sus correlatos más allá. De hecho, los fundamentos del multiculturalismo no provienen de América Latina. El adjetivo "multicultural" es visto por primera vez en 1941 en lengua inglesa, y el sustantivo "multiculturalismo" aparece en los años 1970 en Canadá, Estados Unidos y Australia para referirse a políticas públicas cuyo fin es valorar la diversidad cultural que existe en esas naciones (Doytcheva, 2005).

Sin ignorar la participación de los indígenas en la Asamblea constituyente que dio lugar a la Carta de 1991, es fundamental tener en cuenta que los cambios políticos de la época reflejan un cambio cultural en las élites "blancas" del país - cambio que precisamente está relacionado con la ideología indigenista que nos interesa analizar-. El lenguaje que legitima estos cambios, como veremos, tiene innegables elementos globalizados. Tampoco podemos ignorar el hecho de que dichos cambios se presentan en un momento en que Estados Unidos tiene mayor influencia en la región (Gros, 2003), las políticas neoliberales se consolidan a través de la influencia de organizaciones transnacionales como el Banco Mundial (Domenech, 2007), y las instituciones de la ONU tienen cada vez más presencia en el país, particularmente luego de la firma de convenios como el 169 de la OIT $^{7}$, o a través de la UNESCO, organización que constituye una referencia normativa importante para las instituciones colombianas, difundiendo conceptos como el "diálogo intercultural", la "promoción de la diversidad cultural" o la "preservación del patrimonio inmaterial"8.

Por demás, el discurso de valoración de la etnicidad en América Latina se apoya sobre aquel de los Derechos Humanos (promovido también por la ONU), adquiriendo así una legitimidad "universal" (Bellier, 2006) que pone en evidencia la voluntad de imposición de valores occidentales al nivel planetario. Las acciones de la ONU y del "derecho universalista" (ibíd.) inciden en los Estados del mundo como Colombia, y conducen efectivamente a universalizar la manera en que es tratado el tema de lo étnico (y por lo tanto de lo indígena) en las instituciones estatales. Kaufmann (2004) señala que el discurso de respeto por las diferencias y las minorías étnicas es una imposición de la globalización sobre los Estados-Nación. Refiriéndose al caso colombiano, Urrea (2011) confirma que instituciones supra-nacionales como el Banco Interamericano de Desarrollo o el Banco Mundial han presionado al Estado colombiano para incluir lo étnico como una categoría institucional.

7 "El Convenio número 169 es un instrumento jurídico internacional vinculante que se encuentra abierto para su ratificación y que trata específicamente los derechos de los pueblos indígenas y tribales". (Recuperado en mayo de 2014 del sitio Internet http://www.ilo.org/indigenous/Conventions/nol69/langes/index.htm).

8 Ver por ejemplo la Convención de 2003 de la UNESCO para la protección del patrimonio inmaterial. 
Es paradójico que "los discursos contra la homogeneización cultural en el ámbito mundial y a favor de la diversidad local sean ante todo un producto de la cultura globalizada" (Wood, 1998, p. 224. Nuestra traducción). En efecto, podemos observar que la ONU, organismo globalizado y difusor de la cultura globalizada, busca, por un lado, imponer sus principios y valores supuestamente universales, pero por otro lado, insta a los gobiernos locales (principalmente a través de la UNESCO) a preservar la diversidad cultural (una cierta diversidad cultural únicamente), para lo cual enaltece -como lo hacen nuestros indigenistas conectados con esos valores "universales"- las "sabidurías" y las "espiritualidades nativas"9.

Este marco institucional -nacional y supranacional-que acabamos de esbozar influye en el pensamiento de la población nacional a través de distintos medios, como son las campañas publicitarias, las directrices para las instituciones educativas (desde la primaria hasta la universitaria), las acciones de los Ministerios (por ejemplo en la aplicación del enfoque diferencial) y los programas de múltiples ONG que dicen trabajar por los indígenas.

Desde la institucionalidad académica, una referencia histórica importante fue un pequeño círculo de indigenistas colombianos de la primera mitad del siglo XX, donde encontramos notablemente a Gregorio Hernández de Alba, quien apreciaba la cultura nativa a la vez que criticaba la sociedad europea de su época (Troyan, 2007). Cabe aclarar acá que Hernández de Alba era un eminente académico quien se formó y vivió en Europa, y que el indigenismo colombiano de aquellos tiempos fue, a su vez, precedido por discursos en los que el Otro nativo o no-occidental también era valorado por contraste con la sociedad occidental. Antes de Rousseau y su "buen salvaje", en el siglo XVI, Montaigne (1992) quiso idealizar las virtudes de los habitantes de las Américas, contrastándolas con los vicios de su Europa natal. Y es que, como lo muestra Trouillot (2011), desde Vespucci y Moro, el "salvaje" está asociado a la utopía. En cierta manera, algo similar ocurre en el indigenismo actual, como veremos.

\section{El chamanismo como ejemplo paradigmático de la valoración de lo indígena en la ciudad}

Conceptos como "espiritualidad indígena", "rituales" o "chamán" son frecuentes en diferentes textos a propósito de los indígenas, y son fundamentales para entender la valoración de lo indígena en el país ${ }^{10}$. Por ejemplo, en la prensa o en la televisión, una buena parte de las noticias sobre los indígenas hace referencia a sus creencias y rituales, y muchos de los personajes que suelen protagonizar esas noticias son presentados como chamanes o autoridades espirituales. Por demás, la referencia a la "espiritualidad indígena" es particular-

9 Si algunos individuos u organizaciones indígenas de Colombia y otros países recientemente se han apropiado de una parte de ese lenguaje globalizado, ello se relaciona frecuentemente con estrategias para obtener reconocimiento y beneficios en el contexto de sus relaciones desiguales con la sociedad dominante y con el Estado. A las organizaciones indígenas, como ya se explicó, no las estudiaremos, en la medida en que muy pocos de los indigenistas a los que nos referimos acá tienen contacto con ellas.

10 Para una crítica del concepto de "espiritualidad indígena" como construcción de la población no indígena, ver Sarrazin (2012). 
mente frecuente en los últimos años y se observa por ejemplo en las recientes disposiciones museográficas (notablemente el Museo del Oro y el Museo Nacional en Bogotá), o incluso como estrategia publicitaria para la venta de artesanías, así como para la promoción de paquetes turísticos (Sarrazin, 2011, capítulos V, VII y VIII). Por tomar solo el turismo y la manera en que el imaginario sobre la espiritualidad étnica se manifiesta en otros lugares del planeta, podemos considerar el caso de los medios de comunicación en países como Francia o Estados Unidos, donde se presenta una imagen altamente espiritualizada de la cultura Dogón (Doquet, 2002). Allí se suele dar a entender que el pueblo Dogón sacraliza su entorno y cualquier comportamiento cotidiano. Como consecuencia, los turistas del Norte"1 van a Malí con ese tipo de expectativas, y los actores nativos que se benefician del turismo hacen todo por presentar una imagen que corresponda a aquellas expectativas. De manera similar, un creciente número de turistas europeos vienen a América Latina buscando experiencias chamánicas (Amselle, 2013), lo cual no se debe a sus contactos con las comunidades indígenas que quieren visitar, sino a la información que han recibido sobre el chamanismo a través de los medios. Este fenómeno está también relacionado con el sorprendente aumento de prácticas chamánicas en Europa (Minkjan, 2008), donde citadinos con capital cultural y económico elevado acuden a chamanes de origen americano con el fin de encontrar respuestas a sus inquietudes existenciales.

Si bien desde el siglo XIX el concepto de "chamanismo" fue utilizado por la antropología como una categoría analítica para estudiar un fenómeno propio de grupos aborígenes, desde la segunda mitad del siglo XX -y notablemente en Estados Unidos- este discurso ha empezado a difundirse más allá de la disciplina, llegando a intelectuales de otras disciplinas y a buscadores de prácticas espirituales alternativas (Sarrazin, 2012). Por demás, la presencia de actores no indígenas en prácticas llamadas "chamánicas" ha devenido algo común en diferentes países del mundo (Langdon, 2013). Es así que el concepto de "chamanismo" no lo tomamos como una categoría analítica para el estudio de prácticas que solo ocurrirían en comunidades indígenas; "el chamanismo" o "lo chamánico" son términos cuyo significado ahora depende de los actores que lo usen. Esos usos se han difundido tanto en las sociedades occidentales, que algunos autores (cf. Uribe, 2008) llegan a afirmar (un poco exageradamente) que por "chamanismo" ahora se entiende prácticamente todo lo sagrado que no es monoteísta (p. 117).

En todo caso, el chamanismo, ahora imaginado de manera mucho más generosa que antes, es presentado como un sistema que condensaría toda la filosofía y la sabiduría espiritual indígena. Es el caso del libro que editaron James y Jiménez (2004), donde se presentan discursos fuertemente idealizados sobre el chamanismo y se construye una "cultura indígena" a partir de una serie de ideas provenientes de la filosofía europea, de la mística cristiana o del esoterismo occidental, equiparando la "filosofía indígena" con preceptos de Heidegger, Spinoza, Borges, etc., mezclándolo todo, además, con laxas definiciones del budismo o del sufismo.

11 El "Norte" o "Norte global" está conformado notablemente por las poblaciones dominantes en Norteamérica y Europa Occidental (aunque países septentrionales como Australia y Nueva Zelanda también lo componen). 
El chamanismo es, sin duda, el tema más mediatizado cuando se trata de "aprender de las culturas indígenas". Desde los años 1980, Taussig (2002) anotó que la figura del chamán en Colombia podía ser considerada como una de las manifestaciones más poderosas de mistificación de la alteridad, así como una fuerza trascendente. Sin embargo, si en las zonas rurales de aquella época se hablaba más bien de un "brujo" o "hechicero" que permanecía en la penumbra de la escena pública, actualmente en los medios masivos y en la clase media citadina se habla de chamanes como si fueran figuras que existen en todos los pueblos indígenas; a ciertos chamanes mediatizados se les puede ver incluso en revistas de farándula al lado de estrellas de rock alternativo ${ }^{12}$. Asimismo, cadenas de televisión pública o privada transmiten documentales sobre esos poseedores de una sabiduría espiritual de la cual todos podemos aprender. Se trata de transmitir información para aquellos que quieren "profundizar en su conocimiento de las culturas indígenas y comenzar un proceso de transformación interior"13.

En la historia reciente, uno de los documentales que más ha propulsado el indigenismo actual fue realizado en 1989, no por un colombiano, sino por el británico Alan Ereira, patrocinado por la BBC del Reino Unido. Este documental presenta en un formato místico-esotérico eminentemente atractivo para el público occidental, las creencias de los mamas - autoridades espirituales de la etnia kogui de la Sierra Nevada de Santa Marta- y el supuesto significado del "concepto espiritual de Aluna". En 2014, 25 años después, Ereira aún es recordado y es invitado por la facultad de Administración de la universidad privada más prestigiosa del país, para presentar su nuevo documental, Aluna, y mostrar nuevamente a las élites intelectuales colombianas (incluyendo a los administradores de empresas) su versión de la sabiduría kogui.

Para aquellos que desean vivir en carne propia los rituales chamánicos, los ejemplos más conocidos son las tomas de yajé14. Estas tomas comienzan a realizarse en la ciudad de Bogotá a comienzos de los años 1990 para un público citadino, de clase media y alta, con un nivel elevado de capital cultural y con deseos de conocer un ritual o una terapia exótica para el cuerpo y el alma. No es casualidad que entre estos primeros no-indígenas interesados por las tomas de yajé, se cuenten algunos europeos o norteamericanos, entre los cuales se destaca Jimmy Weiskopf. A raíz de sus experiencias personales en las tomas en Colombia, este estadounidense publica en español y con una editora colombiana de amplia difusión, un libro de gran formato titulado Yajé, el bejuco del alma (Weiskopf 2002), en una clara referencia a lo que llamamos acá la espiritualización ${ }^{15}$ del chamanismo.

12 Revista Shock, N.111, julio de 2004.

13 Palabras pronunciadas por el presentador de un programa de televisión con contenidos sobre salud, terapias alternativas y corrientes espirituales, cuyo fin anunciado es "responder a las preguntas existenciales sobre el sentido de la vida".

14 Para una descripción detallada de estos rituales, ver Ronderos, 2002; Sarrazin, 2008; Uribe, 2002. El yajé o yagé -cuyo nombre científico es Banisteriopsis Caapi- es también conocido en Perú y otros países como Ayahuasca.

15 El concebir una práctica, un discurso o cualquier fenómeno en general como parte de un proceso de aprendizaje para la "transformación interior", es lo que entendemos como su "espiritualización". 
Desde sus orígenes, las tomas (nombre que usamos para referirnos a este fenómeno al que asisten citadinos no indígenas) son valorizadas por personas con una formación occidental, y son objeto de reinterpretaciones marcadas por tendencias culturales globalizadas y originarias del Norte global, lo cual permite, como explicaremos más adelante, que los rituales sean cubiertos de significados místicos y espirituales, o que sean vistos como la ocasión de aprender para un "cambio interior" o una "evolución espiritual". Por otro lado, estas tomas se integran a una lógica comercial globalizada, como la gran mayoría de expresiones urbanas de lo indígena actualmente: se trata no solo de objetos, sino principalmente de mercancías inmateriales identificadas con la etiqueta "indígena" (rituales, terapias, discursos), las cuales, para reproducirse en un sistema dominado por el neoliberalismo, deben poder venderse, es decir, ser apreciadas por un sector de la población con poder adquisitivo.

Todo discurso o imaginario sobre otras culturas o religiones proviene de las condiciones particulares en que viven los autores de esos discursos (Said, 1990). La mayor parte de las representaciones sobre el chamanismo no proceden de lo que los indígenas dicen, sino de toda la información globalizada que consumen los indigenistas. Son estas tendencias culturales las que proveen las grillas interpretativas para que una toma sea considerada como una sesión de psicoanálisis, o que sus resultados se consideren similares a los de la meditación. Igualmente, son esas grillas interpretativas las que permiten valorizar diferentes alteridades étnicas en el mundo, representándolas como fuentes de saberes espirituales o ecológicos. Así, por ejemplo, los medios de comunicación franceses claramente contribuyen a reproducir la idea de un Tibet espiritualizado (Sarrazin, 2014), lo cual se observa de manera comparable en Estados Unidos (López, 2003). Paralelamente, en Occidente se han construido imaginarios positivos de la cultura Hopi (Geertz, 1994), de la cultura Mi'kmaq (Hornborg, 1994), o del Oriente en general (Lenoir, 2000).

\section{Los indigenistas y su indígena auténtico}

Quienes tienen una imagen idealizada y espiritualizada de lo indígena en su gran mayoría no pertenecen a las clases populares, sino que hacen parte de una categoría analítica cuyas características hemos venido describiendo: clase media y alta (típicamente mediaalta), con educación superior, un capital cultural elevado y fuertemente occidentalizado, y un acceso constante a tendencias culturales del Norte global, entre las cuales se incluye, como veremos, la valoración del pluralismo, una preocupación por la salud y el bienestar personal, así como un marcado interés por la espiritualidad, el ecologismo y los viajes.

Estas personas hacen parte de redes sociales en donde todos los individuos no necesariamente se conocen entre sí, y no pertenecen a una organización o grupo auto-definido como tal. Constituyen, en cambio, lo que Castells (2001) llama "redes descentralizadas" que surgen en la "era de la información" y que se forman alrededor de intereses comunes y de valores compartidos. En estas redes descentralizadas surgen ciertos grupos, pero estos son efímeros y los individuos que los conforman no tienen necesariamente vínculos fuertes entre ellos. Una toma de yajé, así como otros tipos de reuniones o rituales 
a los que asisten algunos de estos indigenistas corresponden bien con el concepto de "comunidad de guardarropa" (Bauman, 2000, p. 200), el cual se manifiesta cada vez más frecuentemente en la modernidad tardía, y se refiere a una comunidad que dura lo que dura un evento o una corta serie de eventos en torno a un tema e interés colectivo (una conferencia, un concierto, un ritual, etc.).

Más allá de unas raras y puntuales experiencias exotizadas, las personas estudiadas tienen un contacto muy distante y restringido con individuos indígenas, siendo prácticamente inexistente el contacto con comunidades de estas minorías étnicas ${ }^{16}$. Esto refleja también una realidad presente en otros lugares del mundo occidental u occidentalizado: "los discursos de apertura cosmopolita no provienen de personas integradas socialmente a la diversidad que promueven; emanan de [...] los centros urbanos de poder global" (Friedman 2003, p. 751. Nuestra traducción). Lo que vemos en Bogotá, centro urbano que no puede ser desvinculado de los flujos globalizados y las estructuras globales de poder, es la manifestación local de un discurso pluralista globalizado que avala la tolerancia y la "apertura de mente" hacia la diferencia cultural de origen étnico.

De las entrevistas y observaciones etnografías también se evidencia que los discursos comúnmente hablan de lo indígena en general. En efecto, no se suele hacer la distinción entre las diferentes etnias del país (cuya diversidad lingüística es testimonio histórico de la inmensa distancia cultural que existía entre ellas). Esta generalización permite hablar de los indígenas y su cultura como si se tratara de un todo homogéneo, cerrado y fácilmente aprehensible. Vemos acá un proceso similar al de la construcción de un indígena "hiperreal" (Ramos, 1998): una imagen del indígena construida principalmente a través de los medios de comunicación, considerada por el televidente como más real que los indígenas de carne y hueso; una cultura indígena idealizada, separada de las realidades sociales indígenas y en función de la cual se emprenden acciones individuales o por parte de instituciones como el Estado u ONG con financiación del Norte.

Por eso, de acuerdo con nuestras observaciones, es muy importante considerar el concepto de "indígena auténtico" utilizado por la propia población estudiada. Dicho concepto permite mantener la imagen genérica e idealizada de lo indígena: aunque esa cultura indígena llena de virtudes no la veamos en la realidad social del país (porque solo existe en los medios y en la imaginación de los indigenistas), eso se debería a que la cultura indígena "auténtica" "se ha perdido mucho"; los indígenas "se han contaminado", según palabras de los propios sujetos.

Por otro lado, ese indígena genérico y auténtico permite, entre otras, que se imaginen chamanes prácticamente en todas los pueblos nativos (cosa que hasta hace unas décadas no correspondía con las investigaciones antropológicas), o que se creen organizaciones cuyo objetivo es el de "preservar la cultura" o "rescatar" una esencia indígena cuyas enseñanzas son entendibles como una riqueza espiritual universal. En esta tendencia,

16 Según el último censo oficial de la población (DANE, 2008), en el país el número de indígenas en el país es de 1.392 .623 personas, es decir, 3,43 \% de la población total, pero en la ciudad, este porcentaje sólo alcanza $0.22 \%$ de la población urbana. 
el estadounidense Michael Harner (conocido por algunos adeptos al chamanismo en Colombia), es un célebre ejemplo de un sujeto que funda una organización cuyo fin es unificar el "saber chamánico" del mundo entero en lo que ha llamado el "core shamanism": una sabiduría supuestamente válida y útil para todo ser humano, que él se encargará de difundir en Internet o en forma de libros, talleres y conferencias.

Existen organizaciones criollas cuyos objetivos no distan mucho de la idea del estadounidense. Una de ellas, llamada Raíces del Sur, dice promover y rescatar la tradición cultural y espiritual de América, para darla a conocer como patrimonio de todos los habitantes de la Tierra. Se dice, además, en sus textos que su fundador - un hombre que (itambién!) creció en Estados Unidos-se dedicó a propagar "la esencia de la espiritualidad indígena" realizando temazcales en México y Estados Unidos. Esto, según los textos de la organización, ha servido para crear una alianza inter-tribal de todos los pueblos del continente americano, la cual, además, abre una ventana a la conciencia cósmica de los seres humanos.

De manera análoga, podemos citar también el caso de una organización dirigida por un chaman-coach de origen chileno, la cual, a través de su oficina temporal en Bogotá, ofrece (a precios no abordables por las clases populares) talleres y conferencias. Se trata de una "organización internacional de desarrollo humano y superación personal" cuya misión es "reunir prácticas y filosofías ancestrales con las mejores técnicas de vanguardia del mundo moderno para el desarrollo integral del ser humano". Los clientes de esta organización son profesionales modernos (que también corresponden con la categorización sociológica que hemos hecho del indigenista) en busca de "saberes ancestrales" para el enriquecimiento personal y para "liberarse] de trabas y pensamientos limitantes en la búsqueda de su estado de excelencia".

A pesar de recurrir a una racionalidad de superación individualista y utilizar conceptos ultramodernos como "empoderamiento" o "sinergias", o expresiones en inglés como "coach", "yoga village" o "mindfulness", en estos medios se evoca constantemente el origen indígena de la supuesta sabiduría impartida (la cuestión de la identificación como indígena-tradicional es clave). Gracias a esos conceptos, todos los occidentales podríamos entender cualquier sabiduría milenaria independientemente de su lengua, religión, historia cultural, etc. Se asume que todo ser humano puede entender fácil y rápidamente las lecciones espirituales que yacen en el "fondo" (o "core", si se quiere) de aquellas "culturas étnicas".

Muchos elementos de los discursos indigenistas, ya lo dijimos, se basan en representaciones locales formadas mediante grillas interpretativas provenientes del Norte global. Un ejemplo más de ello es la notable influencia en la población estudiada de autores formados en Norteamérica o Europa, especialmente la del estadounidense Carlos Castaneda (1996), pero también de otros antes o después de él, como George Gurdjieff, Allan Kardec, o Deepak Chopra o Eckhart Tolle. Aunque estos últimos no puedan ser catalogados como indigenistas ni hablen en términos positivos de los indígenas de Colombia, sí han contribuido a espiritualizar la alteridad, sea indígena (en el caso de Carlos Castaneda) u oriental, proporcionando así marcos interpretativos de la alteridad indígena en Colombia. 
A propósito del orientalismo, existe en efecto una vasta literatura sobre la espiritualidad oriental conocida por los indigenistas. Aunque esta literatura hable por ejemplo de la "cultura hindú" o de la "religión budista", prácticamente todo ha sido redactado en el Norte, y originalmente en inglés. Como Said (1990) lo señaló, la producción de textos ha jugado un papel central en la construcción sistemática del conocimiento sobre el "Otro"17. Una forma contemporánea y local de ese orientalismo se manifiesta actualmente también en América Latina. Por además, tal como observa Ramos (2012) en Brasil, existen ciertas correspondencias entre el orientalismo de los europeos, y el indigenismo de los latinoamericanos. En ambos casos se trata de la imaginación de un Otro invariable, genérico y simplificado, pero a diferencia del Orientalismo europeo del siglo XVIII o XIX que describe Said (op. cit.), el indigenismo latinoamericano del siglo XXI se nutre de flujos culturales que circunnavegan el globo en cuestión de segundos.

La combinación de orientalismo e indigenismo que existe en el país hace que las personas "descubran" sabidurías indígenas reinterpretadas en parte a través conceptos que provienen de aquella literatura orientalista. Pero la combinación se manifiesta también a través de prácticas; así por ejemplo, encuentros indigenistas como los de "Raíces del Sur" se realizan muchas veces en lugares orientalistas (con una mejor infraestructura y más antiguos) como es el caso de una "Eco Aldea-Yoga Village", ubicada en las afueras de la capital colombiana.

\section{La alteridad étnica como alternativa globalizada}

Tanto lo oriental como lo indígena se consideran formas de conocimiento útil para la transformación interior y para encontrar alternativas según los ideales y necesidades del yo moderno: calmar su estrés, evolucionar espiritualmente, aumentar su bienestar físico y mental. Todo ello se enmarca, a su vez, en una tendencia más general (y funcional al neoliberalismo) de consumo de la diferencia. Por supuesto, se trata de un consumismo justificado con discursos particulares y "cultos", fruto de un capital cultural relativamente elevado. Las personas que asisten a eventos o rituales o que consumen información relacionada con lo indígena argumentan: "estoy buscando energías positivas"; "busco algo alternativo"; "es importante pensar diferente a la cultura capitalista". Aseguran, además, que "gracias a estas sabidurías, he resuelto problemas internos que traía desde hace tiempo"; "en un ritual uno puede reencontrar el sentido de la vida"; "pienso que gracias a los rituales uno puede reemplazar un psicoanálisis que dura demasiado tiempo".

En sus búsquedas de sabidurías alternativas o de "otros caminos espirituales", los sujetos siguen varios itinerarios, uno de los cuales, por ejemplo, lleva a una persona de su práctica de artes marciales, lo cual la lleva a conocer, en un centro de "meditación

17 Es importante notar que el Orientalismo al que nos referimos acá no es exactamente el mismo tipo de construcción al que se refería Said. Mientras que este autor quería denunciar muchas de las imágenes negativas que se habían producido en Occidente a propósito de los pueblos árabes-islámicos, nosotros nos referimos a las imágenes positivas que existen a propósito de pueblos orientales que no son precisamente árabes-islámicos, sino más bien hindúes, chinos o japoneses. 
trascendental", a otra persona que le recomienda las tomas de yajé. Otro itinerario parte de la visita a un centro de medicina alternativa, donde encuentra información sobre un seminario titulado "El Despertar de la Conciencia", dictado por un médico quien asegura que los chamanes de la Sierra Nevada de Santa Marta practican algo similar al "mindfulness": un concepto que él aprendió en Harvard, y que sería fundamental para el despertar de la conciencia y para que aprendamos a vivir plenamente el presente.

En algunas circunstancias, el orientalismo y el indigenismo se vinculan también al ecologismo, otra tendencia globalizada que refuerza los imaginarios positivos sobre los indígenas, ya que se asume que todos ellos "viven en armonía con la naturaleza" o que son "ecologistas innatos", como decía un entrevistado. Orientalismo, indigenismo y ecologismo se manifiestan en eventos puntuales como los "eco-yoga festivals", los cuales se han realizado en el Jardín Botánico de Bogotá. Allí se ofrecen al público, entre otras cosas, conferencias sobre la espiritualidad indígena, documentales sobre el calentamiento global, así como también clases de yoga, alimentos orgánicos y terapias naturistas para conservarnos sanos y bellos.

Todos estos discursos y práctica relacionados con la valoración positiva de las culturas indígenas van acompañados de críticas explícitas contra "nuestra cultura", "Occidente", "la modernidad" o su "Progreso", el cual estaría destruyendo los saberes ancestrales, así como destruye los recursos naturales y no presenta formas de "vida sana". Se trata, como se ha observado en otros países del mundo, de la búsqueda de una "alteridad espiritual" (Benveniste, Hernandez y Selim 2004; Pons 2004) que contrarreste las tendencias supuestamente demasiado "destructoras", "materialistas" o "deshumanizantes" de la cultura moderna. El indigenismo local, en efecto, utiliza un buen número de ese tipo de ideas, las cuales estaban ya presentes en movimientos nacidos en el Norte global como la "contra-cultura" y el "New Age"18. Hoy en día, ser "contracultural" se ha convertido en un valor ampliamente difundido -incluso y ante todo en Norteamérica-, al punto de que lo alternativo y rebelde se convirtió en un eslogan publicitario de primer orden (Heath y Potter, 2005).

Pero no sobra recordar nuevamente que quienes lanzan este tipo de discursos en contra de la Modernidad, no vienen precisamente de sectores marginales o marginalizados de la modernidad capitalista, y no son precisamente campesinos. Por ejemplo, una ferviente indigenista y promotora de los rituales chamánicos, justifica su posición diciendo que "el Progreso es lo peor". Sin embargo, sabemos que ella es una famosa cantante de rock, que utiliza la última tecnología electrónica para sus creaciones, y que viaja frecuentemente a Estados Unidos (particularmente el Estado de California) para actualizarse en las últimas tendencias y darles a sus canciones -algunas de las cuales hacen referencia explícita a lo indígena- el sonido "cool" que gusta a los rockeros alternativos de Colombia.

18 Sobre las relaciones específicas y complejas que existen entre el indigenismo actual y lo que -no sin controversia- podemos llamar el New Age en Colombia, ver Sarrazin (2012). 
De manera concomitante a lo que hemos observado en este país, Kaufmann (2004) muestra que los discursos pro-étnicos de las élites intelectuales de diversos países en el mundo occidentalizado suelen ser legitimados igualmente a través de la idea de una "crisis de la Modernidad". Si bien es cierto que muchos ciudadanos de las "periferias" del mundo (América Latina, África o India) han participado con sus propios discursos en la difusión del pensamiento crítico en contra del capitalismo o de la Modernidad, la gran mayoría de ellos, como lo demuestra Amselle (2008) y como lo hemos notado entre la población de estudio, han tenido una formación superior de tipo occidental -en las principales universidades de sus tierras natales y/o en países del Norte-, lo cual los ha introducido a teorías críticas (foucaultianas, marxistas, poscolonialistas, decolonialistas, etc.) fundamentadas, estructuradas y legitimadas primeramente en el Norte. Un número creciente de todos estos intelectuales criollos, críticos y amantes de lo alternativo ha decidido publicar en múltiples medios su valoración de ese "otro" indígena, de manera similar a como lo hicieron primero sus colegas en Estados Unidos o en Europa.

Es importante señalar finalmente que ese Otro idealizado y buscado por nuestra población "crítica" es un Otro bien seleccionado y empacado en una bonita presentación étnica, congelada para que se preserve. Esa valoración positiva de lo indígena subsiste solo si se concibe como estática en el tiempo y separada radicalmente de "nuestra cultura occidental"19. Su valor depende de que sea realmente diferente, o "sin contaminarse", para decirlo en términos de la población estudiada. Esta tendencia a concebir al Otro como un ser de una cultura "tradicional", por mucho que haya sido criticada desde la academia, es precisamente una de las ficciones que legitima al indigenismo, y ha estado presente en muchos otros países occidentalizados (ver, entre muchos otros: Briggs, 1996; Haley y Wilcoxon, 2005).

De manera general, la lógica de diferenciación y dicotomización entre un Nosotros y unos Otros ${ }^{20}$, difundida en la Modernidad desde sus orígenes coloniales (Clifford, 1988), persiste gracias a la reproducción de fronteras étnicas imaginarias, las cuales, como lo demostró Barth (1998), no necesariamente están basadas en diferencias culturales reales u objetivas entre los grupos concernidos. La insistencia en esas fronteras es particularmente curiosa en un mundo donde el neoliberalismo se impone con su lema de acabar con las fronteras, y es aún más curiosa cuando quienes insisten en la importancia de esas fronteras para preservar aquella indianidad tan apreciada, sean las mismas personas que aprovechan al máximo el debilitamiento globalizado de las fronteras para viajar, trabajar, conocer y enriquecerse (en todos los sentidos de la palabra).

\section{Conclusiones}

En la medida en que la construcción de imaginarios positivos sobre la indianidad en Colombia no puede ser desligada de tendencias culturales globalizadas, debemos anali-

19 Respecto a esta construcción del indígena como un ser aparte y por fuera del tiempo, la antropología (y la vulgarización de algunas de sus ideas) tiene mucho que ver (Trouillot, 2011).

20 En inglés, esta lógica ya tiene su expresión rimada: The West and the Rest. 
zar el proceso en términos de conexiones a una red planetaria de imágenes y discursos, los cuales son adaptados y referidos a elementos e identidades del país, en un proceso donde interviene la imaginación local. Así, nuevos ideales de humanidad, de relación con la naturaleza, de espiritualidad personal, de salud, etc., han sido traducidos y transferidos a un discurso que incluye una figura local de la alteridad, cual es "nuestros indígenas".

Esta investigación demuestra que una manera particular de representar las culturas, religiones o mitos indígenas permite que las formas culturales más diversas y lejanas entre sí sean consideradas actualmente como portadoras de mensajes profundos y valores morales que la sociedad moderna debería seguir. Este proceso de reinterpretación opera gracias a las transferencias de sentido provenientes de ciertos temas que interesan al sujeto moderno y que hacen parte de tendencias culturales globalizadas. Es por eso que no podremos comprender el sentido que toma actualmente el concepto de "sabiduría indígena", si no lo ponemos en relación con otros conceptos como el enriquecimiento y la realización personal, la búsqueda de espiritualidad, la noción de crisis de Occidente o el constante deseo de cambio entre la población estudiada.

La alteridad nativa ha tomado un lugar preponderante en las representaciones sociales sobre la diferencia cultural, y sirve para imaginar la encarnación de una serie de ideales, valores o intereses que son en realidad los de la población indigenista. Este proceso, como vimos, no es nuevo ni es local. Nuevo, aunque tampoco local, es el concepto de "espiritualidad indígena" mediante el cual se idealiza una alteridad. Esta espiritualización, aunque aparentemente cumpla una noble causa, es una forma contemporánea de conversión de la diferencia en términos atractivos para el consumidor "culto" de la era global: ese yo que constantemente busca (y consume) donde sea, incluso más allá de cualquier tipo de frontera y en cualquier lugar del planeta, diferentes elementos que le permitan realizarse, evolucionar o sentirse mejor.

Pero no debemos limitarnos a constatar que la espiritualidad indígena es en realidad un bien de consumo para una población dominante. Tampoco nos limitamos a decir que en Occidente ciertos grupos sociales utilizan sus propias categorías para concebir al Otro (lo cual no tiene nada de excepcional), y no nos podemos quedar en la confirmación de que el indigenismo se basa en un indígena imaginario y separado de las realidades de las comunidades indígenas. Los puntos más importantes de esta demostración se relacionan con el contexto geopolítico en que se origina el indigenismo, y con las consecuencias de este en el marco de la sociedad nacional.

De antemano cabe notar la arrogancia detrás de suponer que se puede comprender el sistema de pensamiento de otras sociedades en unos cuantos días o meses y a través de unos cuantos conceptos propios (aunque sean muy positivos y generosos, como "espiritualidad", "conciencia cósmica", "mindfulness", "armonía con la naturaleza" "madre tierra", etc.). Esta arrogancia, además, es justamente la que permite, en otros tiempos o espacios, sustentar el racismo cultural o la exclusión de la diferencia, pretendiendo haber comprendido rápidamente sus comportamientos y formas culturales (para discriminarlas y descalificarlas, en este último caso). 
Pero sobre todo, queremos señalar la contradicción del indigenismo que pretende valorar lo indígena y la diferencia cultural, cuando en realidad está reforzando las ideas y valores de sectores privilegiados de la población no indígena: notablemente las élites intelectuales. Por demás, es importante saber que esas ideas que se están usando para representar lo indígena no solo no vienen del contacto con la realidad social indígena, sino que muchas de ellas proceden principalmente del Norte global, y que es allí donde son legitimadas, poniendo de manifiesto una geopolítica de las tendencias culturales. Si bien un indigenista colombiano puede decir "ojalá fuéramos como los indígenas", imaginando a los nativos como modelos, en realidad el modelo del que están hablando y que están difundiendo es el que se plantea en una vanguardia del Norte global. "Ojalá fuéramos como ellos...".

Las ideas y valores de los indigenistas, aunque sean llamados "alternativos" y ciertamente no sean los más comunes porque no son compartidos por las "masas" o los sectores populares, la verdad es que tampoco son ni marginales ni periféricos dentro de la modernidad occidental tardía. Es entonces paradójico que un indigenismo que pretende (quizá muchas veces en buena conciencia) rescatar lo indígena como ejemplo de lo marginal y periférico lo que hace es rechazar la forma de pensar de las clases populares, y reproducir una visión y unos valores que son hegemónicos en el contexto global.

Finalmente, una contradicción más: mientras que el valor de "la cultura indígena" depende de su preservación cultural gracias a las fronteras de las que hablamos, el indigenista valora la apertura de fronteras o la abolición de cualquier límite que restrinja su movimiento y su libre acceso a la información, al consumo, al intercambio y, por consiguiente, a la transformación gracias al contacto con la diversidad sociocultural. Así, el afán del indigenista por preservar la cultura indígena lamenta que los indígenas hagan lo que él más valora para sí: la posibilidad de transformarse gracias al contacto, la posibilidad de abandonar las tradiciones familiares o comunitarias, o la posibilidad de adherir a nuevas espiritualidades.

\section{Bibliografía}

Amselle, J.-L. (2005). Branchements : anthropologie de l'universalité des cultures. Paris : Flammarion.

Amselle, J.-L. (2008). L'Occident Décroché. Enquête sur les Post-colonialismes. Paris : Stock.

Amselle, J.-L. (2013). Psychotropiques. La Fièvre de l'Ayahuasca en forêt amazonienne. Paris : Albin Michel.

Appadurai, A. (2001). La Modernidad Desbordada. Dimensiones Culturales de la Globalización. Buenos Aires: Fondo de Cultura Económica.

Barth, F. (1998). Ethnic Boundaries. Introdution. En: F. Barth (ed.). Ethnic groups and boundaries: the social organization of culture difference (pp. 9-38). Long Grove, Ill.: Waveland Press.

Bauman, Z. (2000). Liquid Modernity. Cambridge: Polity Press.

Bellier, I. (2006). Identité globalisée et droits collectifs : Les enjeux des peuples autochtones dans la constellation onusienne. Autrepart, 38, 99-118. 
Benveniste, A., Hernandez, V., Selim, M. (2004). Praxis Actuelles de l'Imaginaire. Journal des Anthropologues, 98, 43-53.

Bernand, C. E Gruzinski S. (1992). De la idolatría. Una arqueología de las ciencias religiosas. México D. F.: Fondo de Cultura Económica.

Berger, P. E Luckmann, T. (2003). La construcción social de la realidad. Buenos Aires: Amorrortu.

Briggs C. (1996). The politics of discursive authority in research of the Invention of Tradition. Cultural Anthropology, 11(4), 435-469.

Castaneda, C. (1996). Las enseñanzas de don Juan. Una forma yaqui de conocimiento. Buenos Aires: Fondo de Cultura Económica.

Castells, M. (2001). La Era de la Información. Vol. II: El poder de la identidad. México, D. F.: Siglo XXI Editores.

Clifford, J. (1988). The Predicament of Culture: Twentieth-Century Ethnography, Literature, and Art. Cambridge (Mass.): Harvard University Press.

Comaroff, J. E Comaroff, J. (2009). Ethnicity, Inc. Chicago: University of Chicago Press.

D.A.N.E. [Departamento Administrativo Nacional de Estadística] (2008). Censo General 2005. Nivel Nacional. Bogotá: República de Colombia. Documento recuperado el 6 de septiembre de 2008. Disponible en http://www.dane.gov.co/censo/files/libroCenso2005nacional.pdf

Domenech, E. (2007). El Banco Mundial en el país de la desigualdad: Políticas y discursos neoliberales sobre diversidad cultural y educación en América Latina. En: A. Grimson (Comp.) Cultura y Neoliberalismo (pp. 61-89). Buenos Aires: Clacso.

Doquet, Anne (2002). Se montrer Dogon. Les mises en scène de l'identité ethnique. Ethnologies Comparées, 5. Documento recuperado el 14 de septiembre de 2006. Disponible en http://recherche. univ-montp3.fr/mambo/cerce/r5/n.5.htm

Doytcheva, M. (2005). Le multiculturalisme. Paris: La Découverte.

Escobar, A. (1992). Culture, Economics and Politics in Latin American Social Movements Theory and Research. En A. Escobar y S. Álvarez (Eds.). The Making of Social Movements in Latin America (pp. 62-85). Boulder: Westview Press.

Findji, M. T. (1992). From resistance to social movement: The Indigenous Authorities Movement in Colombia". En A. Escobar y S. Álvarez (Eds.). The Making of Social Mouvements in Latin America (pp. 112-133). Boulder: Westview Press.

Friedman, J. (2003). Globalizing Languages: Ideologies and Realities of the Contemporary Global System. American Anthropologist, 105(4), 744-752.

Gaviria, C. (1993). La búsqueda de la armonía perdida. En B. Villegas (Ed.). Indios de Colombia. Momentos vividos, momentos concebidos. Bogotá: Villegas Editores.

Geertz, A. (1994). The Invention of Prophecy. Berkeley: University of California Press.

Gros, C. (2000). Políticas de la etnicidad: identidad, Estado y Modernidad. Bogotá: ICANH.

Gros, C. (2003). Demandes ethniques et politiques publiques en Amérique Latine. Problèmes d'Amérique Latine: politiques et paradoxes de l'ethnicité, 48, 11-29.

Guber, R. (2001). La etnografía. Método, campo y reflexividad. Bogotá: Norma. 
Haley, B. D E Wilcoxon, L. R. (2005). How Spaniards became Chumash and other tales of ethnogenesis. American Anthropologist, 107(3), 432-445.

Hall, S. (1991). The Local and the Global: Globalization and Ethnicity. En A. King (Ed.). Culture, Globalization and the World-System. Contemporary Conditions for the Representation of Identity (pp. 19-39). Binghamton: MacMillan-State University of New York.

Heath, J. E Potter, A. (2005). Rebelarse vende: el negocio de la contracultura. Madrid: Taurus.

Hornborg, A. (1994). Environmentalism, ethnicity and sacred places. Reflections on modernity, discourse and power. Revue Canadienne de Sociologie et Anthropologie, 31(3), 245-267.

James, A. J. E Jiménez, A. D. (Eds.) (2004). El Chamanismo: el otro hombre, la otra selva, el otro mundo. Entrevistas a especialistas sobre magia y la filosofía amerindia. Bogotá: ICANH.

Kaufmann, E. (2004). Dominant ethnicity: from background to foreground. En: E. Kaufmann (Ed.). Rethinking Ethnicity. London: Routledge.

Langdon, E. J. (2013). New Perspectives of Shamanism in Brazil. Shamanisms and Neo-Shamanisms as Dialogical Categories. Civilisations, 61(2), 19-35.

Lenoir, F. (2000). Les Spiritualités Orientales en Occident. En: F. Lenoir, Y. Tardan-Masquelier (Dirs.). Encyclopédie des Religions. Vol. II. Paris : Bayard.

Lopez, D. (2003). Fascination Tibétaine. Paris: Autrement.

Minkjan, H. (2008). Seeking Guidance from the Spirits: Neo-Shamanic Divination Rituals in Modern Dutch Society. Social Compass, 55(1), 54-65.

Montaigne, M. d. (1992). Les Essais. Livre I. Paris: Presses Universitaires de France.

Pineda, R. (2002). Estado y Pueblos Indígenas en el Siglo XX. La Política Indigenista entre 1886 y 1991. Revista Credencial Historia, 146. Recuperada el 6 de Septiembre de 2008.Disponible en http://www. lablaa.org/blaavirtual/revistas/credencial/febrero2002/estado.htm.

Pons, C. (2004). Mediums d'Islande. Globalisation des bien spirituels et routinisation religieuse. Journal des Anthropologues, 98, 55-75.

Ramos, A. (1998). Indigenism. Ethnic politics in Brazil. Madison: University of Wisconsin Press.

Ramos, A. (2012). Indigenismo, un orientalismo americano. Desacatos, 39, 161-184.

Rappaport, J. (2008). Utopías interculturales. Intelectuales públicos, experimentos con la cultura y pluralismo étnico en Colombia. Bogotá: Universidad del Rosario.

Reichel-Dolmatoff, G. (1993). Indios de Colombia. Momentos vividos, momentos concebidos. Bogotá: Villegas Editores.

Sahlins, M. (1997). O "pessimismo sentimental" e a experiência etnográfica: por que a cultura não é um "objeto" em via de extinção (Parte II). Mana, 3(2), 103-150.

Said, E. W. (1990). Orientalismo. Barcelona: Libertarias.

Sarrazin, J. P. (2008). El Chamanismo es un Camino. Las culturas indígenas como fuentes de sabiduría espiritual en Bogotá. En: A. Aguilar et al. (Eds.). Raíces en Movimiento. Prácticas Religiosas Tradicionales en Contextos Translocales (pp. 329-362). Guadalajara: El Colegio de Jalisco/CIESAS.

Sarrazin, J. P. (2011). Du Marxisme au Chamanisme. Naissance d'un indigénisme local à l'heure globale. Sarrebruck: Éditions Universitaires Européennes. 
Sarrazin, J. P. (2012). New Age en Colombia y la Búsqueda de la Espiritualidad Indígena. Revista Colombiana de Antropología, 48(2), 139-162.

Sarrazin, J. P. (2014). Branchés sur la Diversité Culturelle. Enquête sur les représentations et la valorisation du bouddhisme tibétain en Occident. Sarrebruck: Éditions Universitaires Européennes.

Smith, L. T. (2010). Lo nativo y el Down Under neoliberal: neoliberlaismo y las autenticidades en peligro. En M. De la Cadena (Ed.). Indigeneidades contemporáneas: cultura, política y globalización (pp. 369-390). Lima: IEP; Paris: IFEA.

Taussig M. (2002). Chamanismo, colonialismo y el hombre salvaje: un estudio sobre el terror y la curación. Bogotá: Norma.

Trouillot, M.-R. (2011). Transformaciones globales: la antropología y el mundo moderno. Popayán-Bogotá: Universidad del Cauca y Ceso-Universidad de los Andes.

Troyan, B. (2007). Gregorio Hernández de Alba (1904-1973): The Legitimization of Indigenous Ethnic Politics in Colombia. European Review of Latin American and Caribbean Studies, 82, 89-106.

Uribe, C. A. (2002). El Yajé como sistema emergente: discusiones y controversias. Documento del CESO. N. ${ }^{\circ}$ 33. Bogotá: Ediciones Uniandes.

Uribe, C. A. (2008). El yajé, el purgatorio y la farándula. Antípoda, 6, 113-131.

Urrea, F. (2011). Contar y Ser Contados. El Censo 2005 y las Minorías Étnicas. En M. Chaves (Ed.) La Multiculturalidad Estatalizada. Indígenas, Afrodescendientes y Configuraciones de Estado (pp. 67-90). Bogotá: ICANH.

Weiskopf, J. (2002). Yajé. El Nuevo Purgatorio. Bogotá: Villegas Editores.

Wood, R. (1998). Touristic Ethnicity: a brief itinerary. Ethnic and Racial Studies, 21(2), 218-241. 